\title{
Agôn
}

Revue des arts de la scène

Critiques | Saison 2016-2017

\section{Intermède sans titre}

\section{Caroline Châtelet}

\section{OpenEdition \\ Journals}

Édition électronique

URL : http://journals.openedition.org/agon/4027

DOI : 10.4000/agon.4027

ISSN : 1961-8581

Éditeur

Association Agôn

\section{Référence électronique}

Caroline Châtelet, «Intermède sans titre », Agôn [En ligne], Critiques, mis en ligne le 14 juillet 2017, consulté le 14 septembre 2020. URL : http://journals.openedition.org/agon/4027

Ce document a été généré automatiquement le 14 septembre 2020.

Association Agôn et les auteurs des articles 


\title{
Intermède sans titre
}

\author{
Caroline Châtelet
}

Petite inquiétude (sous-titré «Bad news»; surtitré «Wanted»; traduit « What the fuck»; audio-décrit « Est-ce vraiment une nouvelle?»)

1 On a perdu Jean Vilar. Celui dont tout le monde parle à tout bout de champ. LE fondateur du festival d'Avignon, LE nom qu'il est de bon ton de citer quand on veut parler de sa facture d'électricité1. Ou du théâtre populaire, c'est selon. Jean Vilar, mètre étalon du théâtre public, du théâtre populaire, de la démocratisation culturelle et, surtout, surtout, du festival qu'il a créé en 1947 - sous l'intitulé « Une semaine d'art en Avignon ».

2 Enfin, disons que Jean Vilar serait un mètre-étalon à la façon des stoppages-étalon conçus par l'artiste (et joueur d'échecs) Marcel Duchamp (pour voir les stoppagesétalons de Duchamp, clique $\left.\mathrm{ICI}^{2}\right\}$. Le modèle de poids et de mesure n'est pas fixe, avec Vilar. Il est en kit, chacun projetant dans la figure du metteur en scène ses propres références, désirs, contraintes, visions de l'art et de la culture. Bref. Et puis comme toutes les figures tutélaires, on y tient, on s'y tient, mais on les moque aussi un peu. Le conservatisme a besoin de vigies, mais les tourner un brin en dérision permet de faire croire qu'on y met de la distance, de l'ironie, qu'on n'est pas tout à fait dupes de ce qu'elles représentent. Ainsi, régulièrement, Jean Vilar est revisité/détourné sur le mode de la potacherie plus ou moins cinglante.

3 En 2009, à l'occasion de sa programmation dans le cadre du IN, la compagnie LFKS dirigée par Jean-Michel Bruyère diffusait un journal. En résonance à son installation Le Préau d'un seul sur les camps le journal s'intitulait CampCamp ${ }^{3}$, et posait en une de son premier numéro la question «Jean Vilar ou du cochon?» (la réponse étant «du cochon $»)^{4}$.

Dans les bureaux du In, cette année, dans une petite alcôve au détour d'un escalier, le portrait du père s'affichait, renommé «j'envie l'art». Non plus une question, une affirmation, avec un retour de "l'art» depuis longtemps disparu de l'intitulé du festival. Un art désiré, énoncé comme un objectif souhaité, attendu, espéré. Un horizon, en somme. Sauf que voilà. Depuis trois jours, l'alcôve est vide. Est-ce Les Parisiens, création de son successeur l'auteur et metteur en scène Olivier Py, qui marque 
l'abdication d'un bon nombre d'idéaux défendus par Vilar (attention, teasing sur un article à venir), qui l'a décidé ainsi à tout lâcher ? Est-ce la réception critique de ce spectacle? Est-ce la déclaration hier de Régine Hatchondo, directrice générale de la création artistique, aux directeurs de Centres dramatiques nationaux ? (oui, alors, Vilar étant mort, il peut très bien être voyant extralucide et avoir anticipé cette intervention. Donc son départ). Déclaration comportant notamment: "Vous me faites pas rêver... Heureusement que j'ai autre chose que vous dans ma vie "; "Il va falloir quand même penser à faire tomber le mur de Berlin entre vous et le théâtre privé. »

Franchement, aucune idée. Mais nous sommes ouverts à toutes les pistes possibles.

L'alcove de Jean Vilar : était là

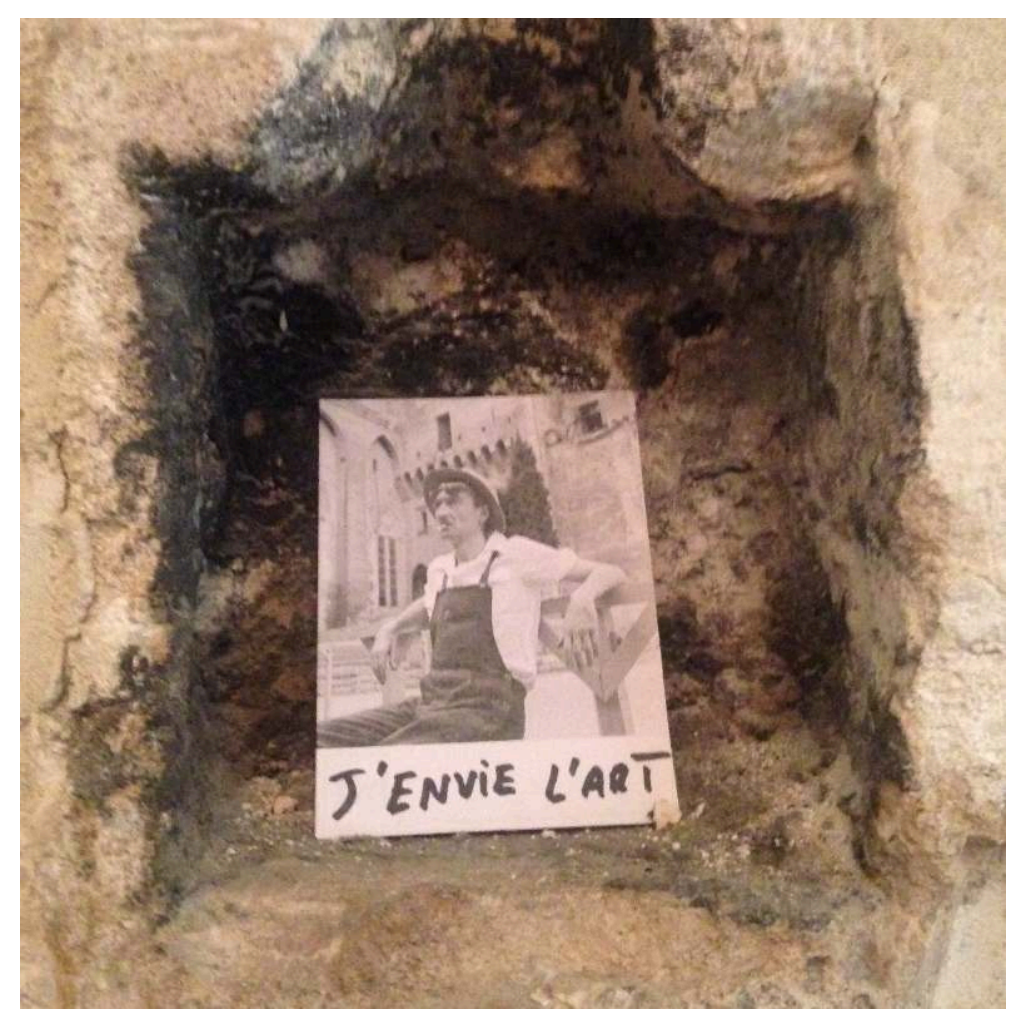

Caroline Chatelet 
L'alcove de Jean Vilar : est plus là

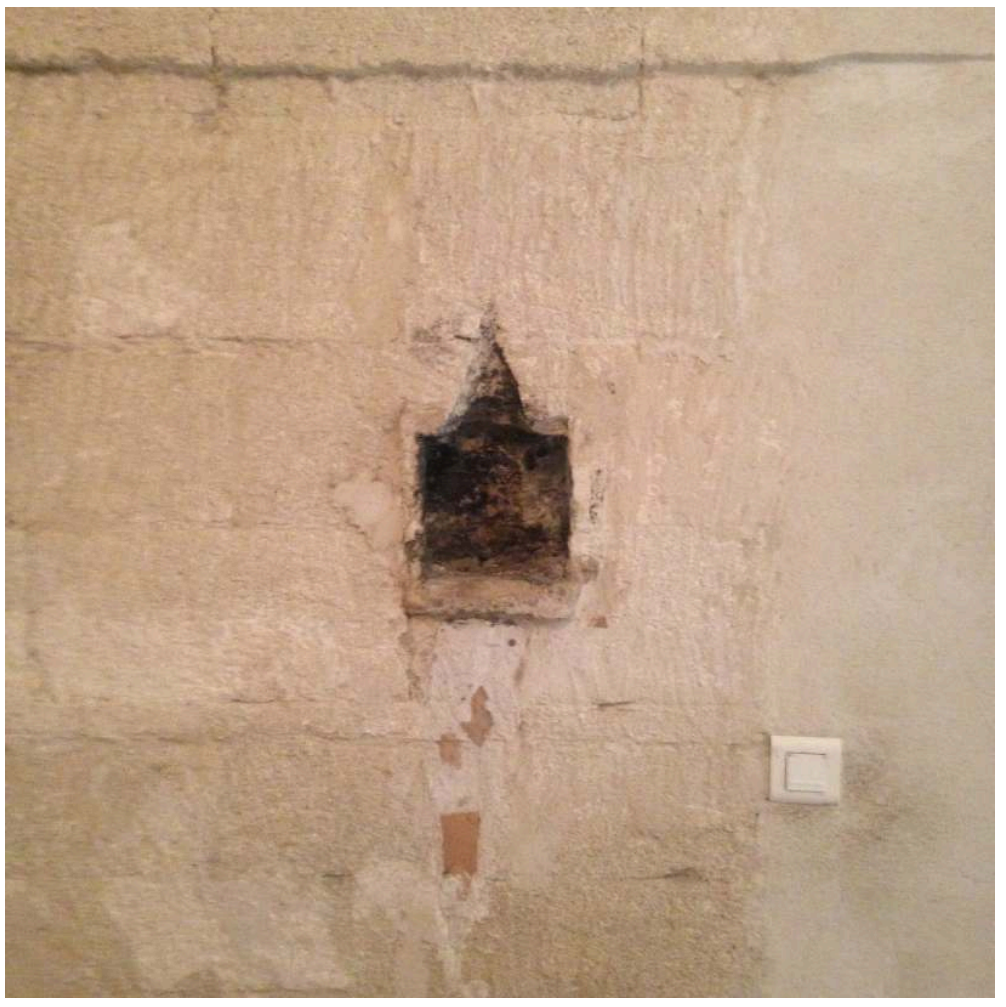

Caroline Chatelet

\section{NOTES}

1. «Le TNP, au premier chef, est un service public, tout comme le gaz, l'eau, l'électricité. » Jean Vilar, « Le TNP, service public » [1953], in Le théâtre, service public, Gallimard, 1986, p. 173.

2. Voir les 3 stoppages-étalon sur le site de Beaubourg: https://www.centrepompidou.fr/cpv/ ressource.action?param.id=FR_R-

c14890bac9d5de17fe43625dd9353c4\&param.idSource=FR_O-60786b89e3957845245f166ae9fa2a2\&param.refStatus=nsr 3. http://www.lfks.net/en/LePreaudunSeul2

4. http://www.lfks.net/sites/default/files/campcamp1.pdf

\section{INDEX}

Mots-clés : Vilar (Jean) 